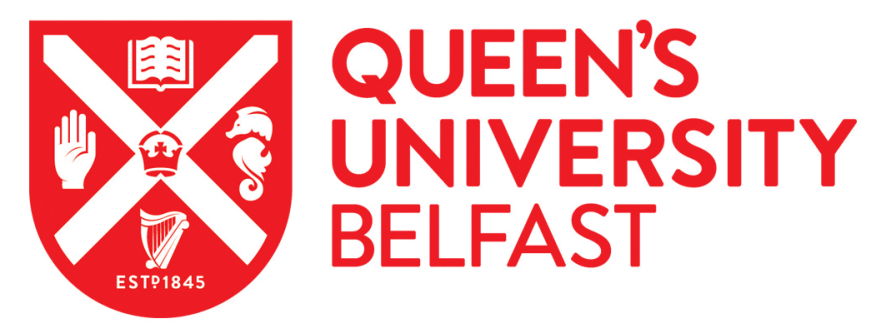

\title{
Assessment systems as cultural scripts: a sociocultural theoretical lens on assessment practice and products
}

Elwood, J., \& Murphy, P. (2015). Assessment systems as cultural scripts: a sociocultural theoretical lens on assessment practice and products. Assessment in Education Principles Policy and Practice, 22(2), 182-192. https://doi.org/10.1080/0969594X.2015.1021568

Published in:

Assessment in Education Principles Policy and Practice

Document Version:

Peer reviewed version

Queen's University Belfast - Research Portal:

Link to publication record in Queen's University Belfast Research Portal

Publisher rights

Copyright 2015 Taylor \& Francis

This is an Accepted Manuscript of an article published by Taylor \& Francis in Assessment in Education: Principles Policy and Practice, 2015, available online: http://wwww.tandfonline.com/10.1080/0969594X.2015.1021568

\section{General rights}

Copyright for the publications made accessible via the Queen's University Belfast Research Portal is retained by the author(s) and / or other copyright owners and it is a condition of accessing these publications that users recognise and abide by the legal requirements associated with these rights.

Take down policy

The Research Portal is Queen's institutional repository that provides access to Queen's research output. Every effort has been made to ensure that content in the Research Portal does not infringe any person's rights, or applicable UK laws. If you discover content in the Research Portal that you believe breaches copyright or violates any law, please contact openaccess@qub.ac.uk. 
To Appear in Assessment in Education: Principles, Policy and Practice, 22(2) 2015.

\section{Assessment systems as cultural scripts: a sociocultural theoretical lens on assessment practice and products.}

\section{Jannette Elwood ${ }^{a}$ and Patricia Murphy ${ }^{b}$}

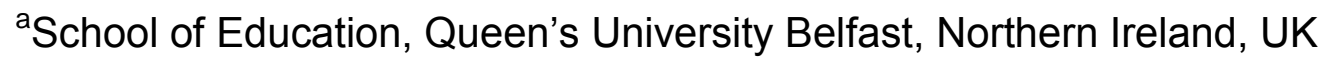
${ }^{\mathrm{b}}$ Faculty of Education and Language Studies, The Open University, England, UK

\section{Introduction}

This Themed Section of the journal aims to extend and enhance ongoing debates within the assessment community that consider the challenges raised by sociocultural theories of learning in presenting a different way in which to understand assessment practice and assessment systems. Moss et al (2008) in their major work in this area, have debated the importance within the field of educational assessment of bringing to the surface the 'tacit assumptions about psychometric and alternative assessment practices' as well as identifying 'the unintended consequences of current assessment practices' and the specification of 'the kinds of knew knowledge that might be needed to inform more constructive and equitable practices in the future' ( $p$. viii). This paper and the others included in this themed section will explore some of the 
challenges for assessment raised by sociocultural theories within both formative and summative assessment frameworks and arenas. Thus we are interested in how claims made about sociocultural theories of learning are informing the expansion of fundamental concepts of assessment and what this ultimately means for assessment practice.

\section{Background}

Key areas of focus within the field of assessment over recent times have been those that have been concerned with students' learning and how best to assess this learning (Hopfenbeck and Stobart, 2015). The dominant debates considered within the field have emerged from research which suggests that more formative approaches to assessment will improve students' learning and hence achievements as defined in assessment regimes. However, while such debates have tended to put individual students' learning at the heart of their considerations and have emphasised 'paradigm' shifts in relation to how the learner and associated assessment practice is viewed, we argue that they have become limited in moving the field forward because they continue to see assessment as separate from the learner, treat learners as autonomous entities in interactions with others and consequently give little credence to the social and cultural mediation of learning and assessing as it is carried out in social contexts of policy systems, schools and classrooms (Elwood 2006; Moss et al 2008; Murphy 2008). Sfard (2008) notes the ubiquity of the term social in discourses about learning in making the point about the confusion that the term engenders in the 'melange' of approaches that purport to be 'social'. For these reasons she refers to the metaphor for learning 
participationism that aligns sociocultural discourses which share a particular meaning of 'social'. In current debates about sociocultural approaches to assessment these confusions about how the individual - social relation is understood are apparent and signify areas of contestation and production when new thinking about the field is being constructed. Acknowledging assessment as a social practice that mediates human relations with the world and with others has attempted to extend these debates. It therefore requires account to be taken in understanding assessment practice of the social, historical and cultural context in which assessment is dialectically constituted. Understanding assessment as an activity involving both process and structure, that address a societal need locates assessment practices in broader systems of relations and social structures in which they have meaning. Assessment practice is both an aspect of the social order incorporated within symbolic networks, and a dimension of social situations in the ongoing activity of institutions where people act together. As part of the social order, assessment is a historically produced discursive construct which acts as a resource to constitute practices. Thus cultural beliefs or 'scripts' about what assessment is and is for, and the ontological and epistemological beliefs embedded within them, are 'conserved, elaborated and passed on to succeeding generations who maintain the culture's identity and way of life' (Bruner, 1996 :3) and become sedimented in expressions of assessments' purposes, uses and practices. Historical and continuing debates about summative and formative assessment have continued to represent them as dichotomous entities and as Black (2001) has warned, have been detrimental to our real understanding about the links between the two. Our position is that 
the application of sociocultural theories raises further challenges for understanding how formative and summative assessments are related, understood and enacted by educators as a duality and not a dualism. These challenges demand that we reconsider and reconceptualise the social construction of assessment and its fundamental and relational concepts, such as validity and reliability, that assessment scholars have held for decades yet have been obdurate to change.

We, and the contributors to this themed section offer some insights into alternative theoretical foundations (both of learning and assessment) on which our present work is based. Such work has looked to foundations of situated and sociocultural theories of learning and the learner, and has started to extend these to practices and understandings of assessment. Such perspectives, that demand the reconsideration of learning and knowledge are raising fundamental questions about assessment systems, uses and practices, in particular the relationships between different purposes and functions, creating tensions between and within different forms of assessment. Yet there is limited literature which demonstrates what this means and what it might look like to conceptualise learning and assessment in the evolving interactions among learners and the various tools or resources that mediate their learning.

In framing the papers in this themed section, we will first explore the notion of cultural scripts within the field of assessment in order to position ourselves and the other contributors within the emerging cultural contexts of knowing, 
learning and assessing. We will then consider the notional dichotomies of formative and summative assessment and the implications of sociocultural theories for these forms and uses of assessment. We will consider them separately, but wish to reflect how sociocultural theories mean that this socalled dichotomy that has plagued the assessment field for many years is deficient and unproductive, and, if anything, needs to be considered as a continuum of practices and processes around socially and culturally constructed artefacts (i.e. tests and assessment tasks).

\section{Assessment: associated cultural scripts}

Education, like other sites of social policy and practice, is exposed to practices beyond the boundaries of the institutions in which it takes place as well as the activities which constitute its make up (teaching, learning, assessing, etc.)(Bruner, 1996). Thus activities within schools and the practices associated with them are part of the broader cultural systems of relations, and social structure in which they have meaning. Summative, and increasingly formative, assessment practices are shaped by broader social and educational policies and structures such as awarding organisations whose practices are legitimated through government regulatory frameworks to develop assessment systems in line with government policies and directives. Such organisations and frameworks reify what constitutes educational achievement and success and shape how we understand educational purposes and the activity of schooling. These reifications project cultural beliefs that circulate and fashion 'intentional activity in the lived-world' (Lave 
1988: 178). These cultural beliefs are embedded in our thinking about learners, learning and assessment and inscribed in our routines and behaviours as we engage with, and in, assessment activity. As learners and their assessors participate in assessment practices they produce, reproduce and transform an instance of 'collective life', of society (Roth and Radford, 2011). Thus aspects of culture, of which assessment is part, exert their influence not just through structural entailments such as educational policies but also through enduring beliefs about how people know and what is legitimated and valued as knowing in society

Perusing the field of assessment, with its attending myriad of research studies, debates, practice, and policy initiatives allows us to consider what the field defines as important and pertinent as well as what it reveals about enduring beliefs regarding assessment. Many factors within education have historically-rooted ideas associated with them, that evidence these 'enduring beliefs' that can also be considered as dominant cultural ways of being or 'scripts' (Ivinson and Murphy, 2007). We argue that the value of a sociocultural theoretical approach to understanding learning and its assessment is that it problematizes_dominant cultural ways of being pertinent to assessment and how these 'ways of being', or cultural legacies have emerged in the field and which are 'rarely acknowledged because ... they are taken-for granted- common sense beliefs, or 'cultural illusions' (p.1). Often what happens in assessment is that, without exposure to alternatives, or understanding of the ways in which assessment interacts differentially with different groups of students, or understanding the ethical and moral impact of 
assessment choices, students, teachers, assessment developers, and policy makers draw on cultural legacies about assessment in relation to how it should be done, what constitutes rigorous and valued assessment and how this should be played out within national and international systems.

Within the field of assessment, the enduring beliefs about products and practices are understood by considering the theoretical positions about what assessment is and what its purpose is, but also theoretical positions about knowledge and about learning and how the two are connected and assessed. Two contrasting cultural scripts have been dominant over the last decades that have become embedded in the cultural ways of being around assessment. First there is the legacy of psychometrics and what its practices suggest about associated theories of learning and knowing. Within this script, the unit of analysis is the individual mind and ontologically mind and brain are the same. Psychometric assessment practices assume the existence of psychological attributes and that observed responses to test items provide evidence about the state or value of these attributes (often innate ability is classified as such an attribute). Knowledge, which reflects an external reality, and learning, are received and fixed respectively; the leaner acquires transmitted that knowledge that is selected form the domain or discipline and this becomes stored and isolated within the individual. In the process of learning knowledge is transferred and received unchanged in its nature and therefore what is learned and what is known is common across learners. Viewing knowledge as an external stable reality treats mind and body as a dualism (Bredo, 1999) separating the individual and the world. 
Consequently social influences are outside of the learner and do not mediate learning or its assessment. Assessment, within this framework is seen as something done to an individual to measure this fixed learning and outcomes are recorded as evidence of this learning (Black 1999; Elwood 2006a). This model also assumes: that tests and assessments are activities that take place in isolation from the teacher and other learners; that assessment tasks are neutral, stable across learners and the testing system itself has no influence on the performances observed; that students responding to test items are isolated from social influences and are thus separately analyzable through the test items used; and that tests or examinations are independently checking up on a student's ability - what students can do on their own.

The psychometric cultural legacy is a powerful one as it underpins much of the world's testing systems and testing industry, (Lemann, 2000). Assessment within this cultural script has moved from local, nation-centric developments and maintaining of systems into the global enterprise of international surveys and comparisons such as the Programme for International Student Assessment (PISA), or Progress in International Reading Literacy (PIRLS), etc. with the associated influences of international bodies (such as OECD) to determine almost all forms of international assessments. The psychometric legacy continues as the dominant discourse internationally around ways of doing assessments, which has become so powerful that associated practices, processes and outcomes have become significant and symbolic levers able to change nations education policy directions world-wide either by coercion or by direct 'action' by naming and shaming those countries not making the grade 
(Stellar and Lingard 2013). Through the psychometric legacy normative statistics of educational achievements have become central in education policy regimes ( Ozga, 2009) and the strength of correlations between achievement and student background measures a surrogate for educational quality and equity at system level (Lingard et al 2014). This 'policy by numbers' phenomenon encourages technical solutions to quality in education systems and allows an evolution from evaluation of 'products' (student achievements) to evaluation of the 'producers' (school systems) (Rochex, 2006).

Second is the legacy of constructivism with its attending principles of human agency and knowledge as co-constructed, with students 'actively making sense of new knowledge, making meaning from it and mapping it into their existing knowledge map or schema' (Gipps, 1999: 372). Activity forms the basis of thinking as learners engage with the world and solve emergent problems. In this engagement learners act on the world and learning occurs through reflection on the consequences of those actions. Thus the view of learning that underpins this cultural script is one where learners are active participants in their learning, that the process of coming to know is constructive and that people are actively engaged in thinking and knowing and that the ideas and experiences we bring to learning situations matter significantly (Murphy 1995). Whilst ontologically constructivism, like psychometrics, assumes the individual mind as the unit of analysis, epistemologically there is a shift which has influenced assessment practice. The epistemological implications of constructivist individual agency is that 
teaching is not concerned with achieving a 'match' between the learner and some external reality but 'fit' between models of learners' notions and operations and adult conceptualizations that allow teachers and their learners to achieve a satisfactory organization of knowledge that is, a 'viable' way of dealing with experience (von Glasersfeld, 1989). This perspective does not challenge task stability as it is assumed that compatibility exists between the assessor's intended meaning and the learner's on the assumption that they do not 'clash', they achieve 'fit' as opposed to 'match'. Though the possibility for different interpretations is recognized 'making sense 'of the task is understood to be inherent in what is being assessed. Constructivist approaches do place emphasis on the need for teachers to use assessment to gain understanding of learners' understandings but still within this position learning is seen as something that belongs to the individual and that assessment tasks are the best way to seek clarification of students' individualized existing knowledge and understanding and to enable then to acquire new knowledge and understanding based on this (Murphy 1995, Black 1999).

The constructivist cultural legacy around assessment has gained prominence with the rise of those who advocate the use of formative assessment to improve learning and the implementation of assessment for learning policies within and across national education systems (Hopefenbeck and Stobart, 2015). The 'Assessment for Learning' movement promotes the position that good formative assessment (that done in classrooms, by teachers with and for their students) will significantly enhance student attainment and develop 
teachers' own assessment and pedagogical practice. Indeed the argument goes further, such that good formative assessment practice that focuses on the quality of feedback to change learning and instruction will help to create greater equity of student outcomes (CERI, 2005). The practices of 'assessment for learning' are concerned with making available learners' understandings for reflection and making explicit and 'transparent the point in the learning pathway towards adult competency which they are aiming for i.e. the learning outcomes and how these are represented in assessment criteria. However, to those of us who are interested in the impact of assessment from an equality and social justice perspective, these arguments tend to be limited in scope and in evidence to sustain such claims (Elwood, 2006b). While proponents of assessment for learning promote the social aspects of classrooms and views of learning within a social arena, they still tend to treat students within these arenas as individuals and only look in to the individual to consider learning and achievement. Constructivist approaches tend to ignore the problematics of assessment as a socially constructed practice, valueladen and affected by the socially constituted nature of individuals in interaction with each other and within the assessment process.

What is becoming evident, is that these dominant cultural scripts within assessment no longer provide a comfortable home for those of us seeking to understand fully the complex interactions of assessment with students and teachers, whether in formative or summative contexts. The prevailing legacies tend to be limited in helping to understand the complex cultural contexts observed within classrooms, the intricacies of teacher-student 
relationships, and the major implications of these interactions for how we assess students.

Thus from within the field of assessment there are emerging new cultural scripts that look to sociocultural theories and approaches to the process of coming to know and what the implications are of such theories for assessment. Thus sociocultural theorists consider a view of learning that takes account of the socially constituted nature of individuals who come to know within their social and historical contexts (Rogoff, 2003), where concepts are socially determined and acquired, and understanding is achieved though individuals appropriating shared meanings through discussion and negotiation. Importantly in sociocultural approaches, individuals' engagement with activities (in this case assessment activities) has 'to take account of the activity, i.e. the larger social, historical, political and economic activities that shape the activity (Murphy, 1995: 252). The challenges that such a perspective holds, demands that we recognize the essential relationship between learning and assessment but that this is affected by the social, cultural and historical lives of students and teachers and the political and economical contexts within which assessment happens. The social and cultural experiences that students and teachers bring to assessment situations cannot be controlled for or ignored they are part of the tapestry of the assessment tasks and outcomes. To understand students' performances on assessment tasks we need to 'look in to their histories and not into their heads' (Elwood, 2006a : 272). 
Furthermore, sociocultural perspectives suggest that meaning derived through interactions is not a product of the person acting rather a product of the relational activities, i.e. that human knowledge is situated in the activity and that meaning resides between individuals. Thus the shift is from the individual self to the relational self and thinking as inherently shared rather than takenas- shared (Roth and Radford (2011). For participationist views of sociocultural theories this means that rather than 'learning 'resulting from the learners' direct efforts to arrive at a coherent vision of the world, participationists see learning as arising mainly from one's attempt to make sense of other people's vision of this world.' (Sfard, 2008 p.131). Consequently individual thinking is understood to originate in interpersonal communication. If 'individual subjectivity and consciousness always and only exists as concrete realizations of collective subjectivity and collective consciousness' (Roth and Radford, 2011p. 141) then how we understand, assess and interpret measures of individual achievement requires a significantly different epistemology to that of psychometric, constructivist discourses and approaches. It is to these challenges of sociocultural theories for formative and summative assessment activities and systems that we now turn.

\section{Sociocultural theories and formative assessment}

Formative assessment in classrooms, focusing on teachers and students, their experiences and shifts in understanding and practice seems to be, at present, the main spaces were researchers, interested in assessment practice, are invoking sociocultural theories to understand the human 
processes and interactions that emerge within different subject contexts as students with their teachers and peers interact. By the very nature of these studies, evidence is collected from small-scale settings and focuses on the emergent, the dynamic of interaction, as this is where formative action is seen to occur in the 'generative dance' (Cook and Brown, 1999). Formative action to enable learning and support learner agency from a sociocultural view necessarily focuses attention on the collective wherein knowledge is made available for individual appropriation (Rogoff,1995). The assumption that there is only one kind of knowledge and the privileging of individual over collective knowledge enshrined in the psychometric and constructivist perspectives we discussed earlier, is at odds with a sociocultural approach to formative assessment. A sociocultural epistemology requires an expansion of what is recognised as epistemic and within that, recognition that individual and collective explicit and tacit knowledges are distinct forms of knowledge which do different epistemic work (Cook and Brown, 1999). Formative assessment practices at the very least need to expand and pay attention to these. Cook and Brown (1999) further argue that what learners know how to do is not reducible to forms of knowledge but requires understanding of the epistemic work done by human action. To bring together notions of individual and collective action and to begin to expand what we understand as epistemic requires in addition an epistemology of practice. Hence there are two dimensions that are 'mutually enabling' the distinct forms of knowledge used in action and knowing as 'part of action' (Cook and Brown , 1999 p.53). It is the interplay between these dimensions that are potentially generative and it is within this that formative action is enabled. Sociocultural studies of 
formative assessment and of the relationship between formative and summative assessment have begun to explore new understandings of what and how people know in relation to collective human activity. The focus on learning discourses emergent in settings and on the dynamic affordances within it are seen as fundamental, if we are to know more about 'what' assessment is, how it can be used to interact with knowledge, context and teaching to enable learning and what aspects of teachers' practice in interaction with students' learning can be described within subject contexts so as to enhance the experience of students and teachers in classrooms.

While formative assessment seems to be a space where sociocultural theories of learning have been invoked to give a fuller understanding of emerging and interactional practices, there are still limits to assessment being understood as a social practice with associated cultural artefacts, tools and language. There are still challenges raised by sociocultural theorising for how formative assessment is considered. This is further compounded within educational institutions where institutional practices reflect how participants respond to social order influences and structures with the continued but different cultural responses to summative assessment. Thus to understand the emergent where formative assessment is enacted requires attention to the dialectical relationships between social order structures and influences, institutional practices and the social actors' histories of participation in assessment practices. Thus crucially, from a sociocultural perspective, assessment systems, summative and formative assessment practices and responses to them are understood as mutually constitutive. 


\section{Sociocultural theories and summative assessment}

If within a sociocultural framework, long-established assessment concepts no longer hold firm then what impact does that have on how we view assessment at the system level and what might be the consequences for summative assessment, especially that which is high stakes for students? As discussed above, sociocultural theories align with a world view that suggests that summative assessment, like formative assessment, is not neutral and that even if test developers work diligently at establishing the best assessments they can for particular required purposes, the social practice of assessment will mean that the assessments will not operate in practice as they have been statistically or theoretically developed to do. Thus sociocultural theories suggest that at the summative assessment level, a theory of response is needed. This is because even at the level of test items, the interaction of the learner and the construct being assessed changes the construct and these become emergent rather than fixed. Just as the learner and teacher are changed by interactions within formative assessment, so too are learners and their responses changed through interaction with constituent items on summative tests. Sociocultural theories also raise questions about what constitutes 'data' given its emergent and often unconscious and invisible nature. 'Data' within the other cultural legacies of assessment outlined above is based on models of fit for specific purposes that are enacted to produce valid and reliable data within error parameters. This suggests that challenges also exits for how we understand assessment data and how we speculate about the data upon which achievement 'results' are based. 
In terms of summative assessment, socio-cultural theories would start to suggest that while the developers of such assessments define the purposes of assessment and set assessments to meet these, often the consequences of assessment use are that outcome measures are used for multiple purposes which ultimately are in tension with the initial purposes for which the assessment was defined, and indeed questions whether or not the initial purposes can be met. Fundamentally, purposes of summative assessment raise the visibility of reliability of the assessment, which again moves away from the individual test taker and their interaction with the tasks set to the focus on the assessment overall. Attendant to the cultural script of the psychometric and constructivist models discussed above is the suggestion that assessment developers do not see themselves as responsible for the uses to which assessment outcomes are put; they are not about the consequences of what they do. This in itself assumes a view of practice at odds with sociocultural theorising.

Fundamental to sociocultural approaches to assessment, is a consideration that the practice is not neutral. The norm tends to be that the social world starts to use summative assessment in ways that reify it and the practice of summative assessment becomes 'scientifically' of value. Thus a sociocultural position would be concerned with questions regarding the reification of summative practices and outcomes, even down to the item level. Assessment scores obtained by learners are not objective, nor can they be considered without reference to the items on the test, the make-up of the test 
and the way in which learners have been prepared for the test itself. Such factors we argue cannot be left out of the consideration of assessment outcomes; the chimera of reliability is exactly that when such a concept is viewed through a sociocultural lens. Messick (1981) supports us in the need to recognise the limits of what is being done. Thus our position is that a pragmatic but theoretically aligned response is to treat assessment as a social practice; doing and becoming an assessed school learner involves

understanding the practices that students have to engage in, which assumes that such practices and activities are something within teachers' expertise and that they are aware of how progression or becoming expert and assessment literate can be achieved.

\section{Contributions to the themed issue}

Thus through this introductory paper and the contributions that follow we aim to introduce, extend and enhance ongoing debates that consider the challenges raised by sociocultural theories for assessment and associated aspects of knowing and learning. As with any family of theories there are different variations and interpretations of meaning, and it is no different within this set of papers here. We have a particular sociocultural view that we have outlined in this background paper that others who use the term do not share, including the contributions that follow. However, we would argue that this is legitimate in a field that is emerging. Not all our contributors would acknowledge that they are socioculturalists, but what they are prepared to do is to reconsider aspects of assessment practice that have held firm for too long both at the system level and at the classroom level. Each contribution 
makes a particular case for considering assessment 'givens' in a different light and the implications of this for assessment practice.

The paper by Goldstein presents us with his interrogation of the term validity, which he acknowledges is one of the most important, debated and contested terms in assessment. He suggests that to unify all the differing approaches to validity we need to consider an associational perspective, where basic scientific ideas would provide new ways of considering old dilemmas within validity. His stance sits, if not wholly then tangentially, within the emerging ideas of sociocultural approaches in that he is advocating that perennial ways of considering validity have never really provided sound solutions to understanding its impact on the processes and practices of test construction nor on providing clear ways of considering the assumptions of those who use and take the test. In a sociocultural framework, the interaction of the test constructors, test users (teachers and students) and test outcomes needs to be considered when validity arguments come into play

Hickey details work from a range of research studies that have used situated approaches to consider the real value of formative assessment to the improvement of teaching and learning. He uses his data to argue that while formative assessment is popular, its efficacy is perhaps not as considerable as its proponents would wish it to be as it is, as he points out, difficult to evaluate and thus to see how improvements are being made. Thus he advocates the uses of situated theories to the consideration for formative assessment as they offer solutions to the difficulties in understanding the 
entangled nature of teaching and assessing and how dichotomies of formative/summative and function/purpose do not reflect the complexities of assessment activities in classroom settings. He foregrounds a continuum of 'assessment formality' in order to align learning across different assessments and consider a spectrum of different functions emerging from the same assessment activities.

In her paper that considers schools as living sites of evidence-based practice, Fleer details research, carried out with teachers over time, that used cultural historical concepts to reconsider their own assessment practice in the primary sphere. She emphasises key situational concepts (after Vygotsky) such as the zone of proximal development, motives, and the relations between real and ideal forms of development that were used with teachers from one primary school in order that they might change their assessment practices. Fleer foregrounds the tensions and struggles that emerged for teachers as they worked against the dominant cultural scripts of assessment as dictated to them by educational authorities and state-wide assessment programmes. She considers too the main categorising factor of 'age' and how assessment in its dominant form relies on age as a key organising variable in terms of establishing where a child is in terms of achievement and what a child should know. Fleer describes how situational theories of knowing and learning enabled teachers to reconceptualise and enact assessment so as to form new assessment pedagogies within their own immediate context. 
The paper by Cowie and Moreland focuses on the relational aspects of disciplinary knowledge, classroom learning and assessment. They too highlight detailed, observational work with teachers as a way of looking at, and reconceptualising teaching and learning and how assessment needs to be part of this. They adopt a sociocultural lens to enable them to explore how students' appreciation of their teachers' use of disciplinary norms and practices within a classroom community of scholars (pupils and their teacher) helped them experience how knowledge in the social is co-created and emergent. They foreground the notion that when sources of 'authority' are ultimately distributed between pupils (peer-to-peer) and between teachers and pupils, learning is experienced as the development of autonomy and discernment. 
References

Black P. 1999. Assessment, learning theories and testing systems. In P. Murphy (Eds.) Leaners, Learning and Assessment (pp. 118-134). London: Paul Chapman.

Black, P. 2001. Dreams, Strategies and Systems: portraits of assessment past, present and future. Assessment in Education, 8, 65-85.

Bredo, E. 1999. Reconstructing Educational Psychology. In P. Murphy (Ed.) Learners, Learning and Assessment. (pp. 23-45). London: Paul Chapman/SAGE.

Bruner, J. 1996. The Culture of Education. Harvard: Harvard University Press.

Centre for Educational Research and Innovation (CERI). 2005. Formative Assessment - Improving Learning in Secondary Classrooms. Paris: OECD.

Cobb, P. 1999. Where Is the Mind? In P. Murphy (Ed) Learners, Learning and Assessment. (pp. 135-150). London: Paul Chapman/SAGE. 
Cook S. and Brown J. 1999. Bridging Epistemologies: The Generative Dance Between Organizational Knowledge and Organizational Knowing. Organisation Science, 10, 381-400.

Elwood J (2006a) Gender Issues in testing and Assessment. In C. Skelton, B. Francis, and L. Sumyan (Eds.) The SAGE Handbook of Gender and Education, (pp. 262-272). London: SAGE.

Elwood J (2006b) Formative assessment: possibilities, boundaries and limitations. Assessment in Education: Principles, Policy \& Practice, 13, 215232.

Gipps, C. 1999. Socio-Cultural Aspects of Assessment. Review of Research in Education, 24: 355-392.

Hopfenbeck, T. and Stobart G. 2015. Large-scale implementation of Assessment for Learning. Assessment in Education: Principles, Policy and Practice, 22, 1-2.

Lave, J. 1988. Cognition in Practice. Cambridge: Cambridge University Press.

Lave J. and Wenger, E. 1991. Situated Learning: Legitimate Peripheral Participation. Cambridge: Cambridge University Press. 
Lemann, N. 2000. The Big Test: The secret history of the American meritocracy. New York: Farrar, Straus and Giroux.

Messick, S. 1981. Evidence and ethics in the evaluation of tests. Educational Researcher 10, 9-20.

Moss,P., Pullin D., Gee J., Haertel, E. and Jones Young, L. 2008.

Assessment, Equity, and Opportunity to Learn Learning in Doing: Social, Cognitive and Computational Perspectives. New York: Cambridge University Press.

Murphy, P. 1995. Sources of inequity: understanding students' responses to assessment. Assessment in Education: Principles, Policy and Practice, 2,249270.

Murphy P. 2008. Gender and subject cultures in practice. In P. Murphy and K. Hall (Eds.) Learning and Practice: Agency and Identities (pp. 161-172). London: SAGE

Ozga, J. 2009. Governing education through data in England: from regulation to self-evaluation. Journal of Education Policy, 24, 149-162.

Lingard, B., Sellar, S. and Savage G. 2014. Re-articulating social justice as equity in schooling policy: the effects of testing and data infrastructures. British Journal of Sociology of Education, 35, 710-730. 
Rochex, J-Y. 2006. Social, Methodological, and Theoretical Issues regarding Assessment: Lessons from a Secondary Analysis of PISA 2000 Literacy Tests. Review of Research in Education. 30, 163-212.

Rogoff, B. 1995. Observing sociocultural activity on three planes: participatory appropriation, guided appropriation and apprenticeship. In J. V. Wertsch, P. Del Rio and A. Alvarez (Eds.) Sociocultural studies of mind. Cambridge: Cambridge University Press.

Rogoff, B. 2003. The cultural nature of human development. Oxford: Oxford University Press.

Roth, W. M. and Radford, L. 2011. A Cultural-Historical Perspective on Mathematics Teaching and Learning. Rotterdam: Sense Publishing.

Ivinson, G and Murphy P 2007. Rethinking single-sex teaching: gender, school subjects and learning. Berkshire, England: Open University Press/McGraw-Hill Education.

Sellar, S. and Lingard, B. 2013. The OECD and global governance in education, Journal of Education Policy, 28, 710-725

Sfard, A. 2008. Particaptionist Discourse on Mathematics Learning. In P. Murphy and K. Hall (Eds.) Learning and Practice: Agency and Identities. (pp. 120-131). London: SAGE 
Von Glasersfeld, E. 1989. Learning as a constructive activity, in P. Murphy and B. Moon (Eds.) Developments in Learning and Assessment. London Hodder and Stoughton. 